RESEARCH ARTICLE

\title{
Nasal Manifestation of Herpes Simplex Virus And Recovery with Antimicrobial Phthalocyanine Derivative Protocol
}

\author{
Vivian Palata Viola ${ }^{1}$, Fabiano Vieira Vilhena ${ }^{2}$, Paulo Sérgio da Silva Santos ${ }^{1}$ \\ ${ }^{7}$ Bauru School of Dentistry of University of São Paulo, Department of Stomatology, Radiology and Imaging, Sao \\ Paulo, Brasil \\ ${ }^{2}$ Trials, Oral Health and Technologies, Sao Paulo, Brasil
}

\begin{abstract}
Female patient, re-infected with Herpes Simplex Virus (HSV) with pain associated with symptoms, usually using antivirals for treatment. The patient was instructed to use an alternative nasal spray containing an Iron Phthalocyanine Derivative (IPD) in place of the previous treatment and presented rapid improvement of symptoms and injuries after use. J Microbiol Infect Dis 2021; 11(4):241-242.
\end{abstract}

Keywords: Stomatitis, Herpetic, Herpes simplex, Oral medicine

\section{CASE SUMMARY}

A 38-year-old female reported to be re-infected with Herpes Simplex Virus (HSV) six years after the first infection. The diagnosis was made based on the clinical examination, wich revealed the presence of grouped vesicles in the intranasal epthelium (Figure 1), and on the patient's historic of recurrent herpes simplex infections, diagnosed with microbiological criteria at previous times. She reported that this was generally a painful period that could be relieved with the use of camphorated phenol gel (topical application 3 times a day, five days) plus acyclovir (two pills a day, seven days).

The patient was instructed to use an alternative nasal spray containing an antimicrobial Iron Phthalocyanine Derivative (IPD) in place of the previous treatment. The protocol consisted of two pumps in each nostril 5 times/day for one week, in association with systemic antiviral therapy.

The lesions disappeared after one week of treatment (Figure 2), as reported by the patient and confirmed by clinical examination. Moreover, the patient reported that there was no more pain and nasal lesions $48 \mathrm{~h}$ post-start of the rinsing protocol.

HSV causes recurrent painful vesicular eruptions mainly affecting the orolabial and genital mucosa [1]. IPD is an antiviral selfactivated bioactive compound that acts on the production of reactive oxygen species [2-4].

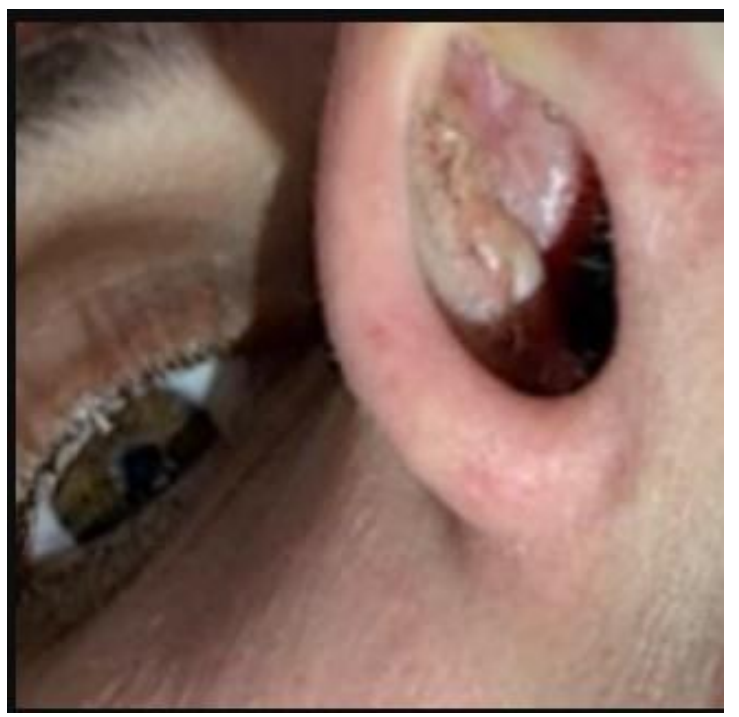

Figure 1: Initial clinical situation at day one.

The two-month follow-up of this case suggests that the APD protocol has a potential against herpes, as there were no new lesions in the orolabial and nasal region according to the patient's report and clinical examination. These results are in accordance with the literature, since IPD have demonstrated promising results such as antiviral (SARSCoV-2), anti-inflammatory, pain reduction, and oral soft tissue regeneration effects [2-4]. Larger randomized clinical trials are warranted.

Correspondence: Paulo Sérgio da Silva Santos, Alameda Octávio Pinheiro Brisolla, 9-75, Vila Universitária, Bauru, São Paulo, Brazil 


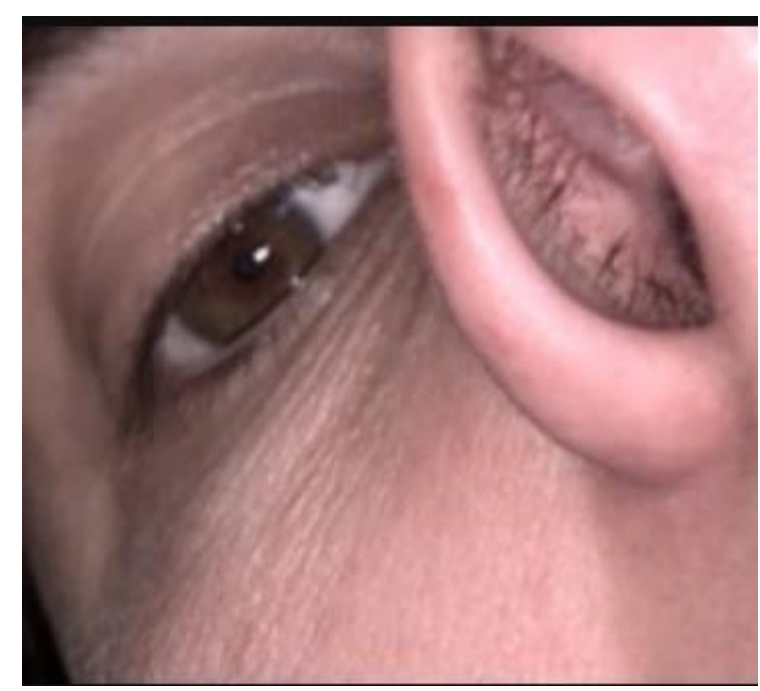

Figure 2: Clinical situation one week post-start of the antimicrobial phthalocyanine derivative protocol.

\section{ACKNOWLEDGMENTS}

Declaration of conflicting interest: The author(s) declare no potential conflicts of interest concerning this article's research, authorship, and/or publication.

Financial disclosure: No financial support was received for this study.

\section{REFERENCES}

1. Ramchandani $M$, Kong $M$, Tronstein $E$, et al. Herpes Simplex Virus Type 1 Shedding in Tears and Nasal and Oral Mucosa of Healthy Adults. Sex Transm Dis 2016;43:756-760.

2. Santos C, da Fonseca Orcina B, Brito Reia VC, et al. Virucidal Activity of the Antiseptic Mouthwash and Dental Gel Containing Anionic Phthalocyanine Derivative: In vitro Study. Clin Cosmet Investig Dent 2021;13:269-74.

3. Orcina BF, Santos PSS. Oral manifestation COVID-19 and the rapid resolution of symptoms post-Phtalox treatment: a case series. Int $\mathrm{J}$ Odontostomat 2021;15:67-70.

4. Semetana Z, Bem-Hur E, Mendelson E, Salzberg S, Wagnar N, Malik Z. Herpes simplex vírus proteins are damaged following photodynamic inactivation with phthalocyanines. J Photochemist Photobiol 1998; 44:77-83. 